\title{
Uma riqueza nas matas meridionais: a extração da erva- mate no século XIX na província do Rio Grande do Sul
}

\section{A wealth in southern forests: the extraction of yerba mate in the nineteenth centuryin Rio Grande do Sul Province}

Cristiano Luís Christillino - Pós-Doutor em História pela Universidade Federal de Pernambuco (2012). Professor Adjunto da Universidade Estadual da Paraíba. Professor colaborador no Programa de Pós-Graduação em História da Universidade Federal de Pernambuco/UFPE. E-mail: christillino@hotmail.com

\section{Resumo}

O objetivo deste artigo é analisar a importância econômica da erva-mate no processo de colonização do sul do Brasil no século XIX. Mostramos que, diante dos baixos lucros obtidos com a pecuária, a elite fundiária se apropriou de vastas extensões de ervais, especialmente na segunda metade do XIX. Na Província do Rio Grande do Sul esta atividade extrativa permitiu aos fazendeiros e aos comerciantes uma rápida acumulação de capital. A lucratividade com o mate também foi o estímulo econômico à grilagem de terras florestais. A exploração dos ervais localizados no oeste da Província de Santa Catarina pelos argentinos levou o Governo Imperial a intervir na região. A exploração da erva-mate empregou uma mão de obra tão extensa quanto a pecuária, e permitiu a expansão do universo social dos "homens livres e pobres".

\section{Palavras-chave}

Erva-mate. Recursos naturais. História agrária. Lei de Terras. Brasil Meridional.

\begin{abstract}
The purpose of this article is to analyze the economic importance of yerba mate in the process of colonization of southern Brazilin the nineteenth century. We show that, given the low profits from livestock, the landed elite appropriated vast tracts of herbal, especially in the second half of the nineteenth. In the Rio Grande do Sul Province this extractive activity allowed farmers and traders, a rapid accumulation. Profitability with yerba mate was also an economic stimulus for grabs on forest lands. The exploitation of herbal located in the west of the Province of Santa Catarina, by the Argentines, led the Imperial Government to intervene in the region. The exploitation of yerba mate hired a skilled workforce as extensive as the one used in livestock, and allowed the expansion of the social universe of "poor free men" in nineteenth-century Brazil.
\end{abstract}

\section{Keywords}

Yerba mate. Natural resources. Law of Land. Agrarian history. Southern Brazil. 


\section{INTRODUÇÃO}

A erva-mate é produzida a partir das folhas da Ilex paraguariensis, árvore abundante nas regiões de clima subtropical da América do sul, presente na região Sul do Brasil, no Mato Grosso, no norte da Argentina e no Paraguai. A cultura de erva-mate foi a maior economia extrativa das fronteiras do Brasil com o Prata no século XIX. A produção da erva-mate foi a segunda atividade de exportação mais importante da Província do Rio Grande do Sul entre as décadas de 1840 e 1870, quando a agricultura, expandida nas áreas coloniais, ultrapassou os números da erva-mate no comércio da província com as demais regiões do Brasil e com o exterior. A extração do mate era realizada em meio às matas nativas, a cada quatro ou cinco anos, período em que as árvores de Ilex paraguariensis levavam para regenerar os seus ramos, pois a colheita em período menor comprometeria a vida útil das árvores, visto que, no século XIX, ainda não havia plantios comerciais. A colheita do mate era realizada principalmente nas serras do município de Cruz Alta, mas também se expandia pelas escarpas de montanha de Cachoeira, Triunfo, Rio Pardo e Taquari. No caso destes dois últimos municípios, o francês Aimé Bonpland afirmou em seu relatório de viagem que a erva-mate era uma das três árvores mais abundantes em suas matas (LINHARES, 1969). A extração dessa riqueza empregou a mão de obra de milhares de homens livres.

A erva-mate também assumiu um papel de destaque na Província do Paraná, sendo o seu principal produto de exportação entre 1853, data da sua criação, até a crise de 1929 (SANTOS, 1995), assim como foi a principal atividade do oeste da Província de Santa Catarina no século XIX (MACHADO, 2004). O mate também foi explorado na Província do Mato Grosso, cujos ervais foram alvo de disputas entre o Brasil e o Paraguai (BANDEIRA, 1985). Nesse período, a produção brasileira era exportada principalmente para o Uruguai, Chile e Argentina.

Há um problema com as fontes fiscais sobre estas atividades na América espanhola, fato que não permite um detalhamento da sua importância, uma vez que a produção não era exportada para a Europa, como a prata de Potosí, o couro e outros subprodutos vacuns, de forma que dispomos de poucos dados acerca dessas atividades. Mas a historiografia mostrou que os centros mineradores como o de Potosí, além de outros núcleos populacionais importantes engendraram uma "cadeia de efeitos" e criaram espaços comerciais para outras atividades, incluindo o mate. Os ramos do mate, secos, tostados e moídos eram utilizados pelos guaranis para a infusão de uma bebida que posteriormente ficou conhecida como mate ou chimarrão, e foi difundida até mesmo entre os trabalhadores das minas de Potosí, ainda no século XVII (LINHARES, 1969, p. 34). 
A exploração comercial do mate iniciou com nas reduções da Província Jesuítica do Paraguai, e depois foi expandida para as demais regiões da Bacia Platina. De acordo com Temístocles Linhares (1969), o consumo de erva-mate difundiu-se rapidamente entre os colonizadores espanhóis e portugueses. Entre estes últimos, os tropeiros disseminaram o uso do mate até a Província de São Paulo. O mate foi um dos produtos comerciais mais expressivos também na praça comercial de Buenos Aires ao longo dos séculos XVIII e XIX, o que refletia a sua importância na Região Platina. O mate não só foi responsável por boa parte dos negócios realizados naquela praça, como integrou economicamente várias localidades e povos indígenas à capital portenha (GARAVAGLIA, 2008). A erva-mate também foi um estímulo econômico à ocupação do planalto do Rio Grande do Sul.

\section{O MATE NA ECONOMIA DO RIO GRANDE DO SUL}

Após o Tratado de Madri, de 1750, quando o território dos Sete Povos das Missões foi entregue aos portugueses, muitos negociantes de couro de gado, tropeiros, ${ }^{1}$ seus peões e escravos se deslocaram para o Planalto do Rio Grande do Sul em busca dos rebanhos da Vacaria dos Pinhais. A erva-mate era uma base econômica importante das Missões e, com a destruição dos Sete Povos na Guerra Guaranítica (1753-1756), o produto passou a ser explorado na região pelos súditos da Coroa portuguesa. A maioria dos tropeiros que percorria o Planalto rio-grandense-do-sul não eram militares de alta patente que pudessem receber concessões de terras, nem tinham capital suficiente para adquirir rebanhos a fim de ocupar a terra ou então comerciá-los no Sudeste. Portanto, a solução para esses "remediados" foi a exploração da erva-mate. Eles reuniam seus parcos recursos, escravos e agregados e montavam carijós para o beneficiamento do mate. Esses tropeiros "remediados" negociavam a erva obtida em troca de mulas e rebanhos bovinos com comerciantes estabelecidos junto ao rio Uruguai. Esses animais eram invernados no Planalto ou nas Missões, até que formasse um rebanho com número suficiente para ser tropeado até as feiras de São Paulo, um ciclo que poderia durar até cinco anos. A erva-mate permitiu a um número razoável de pessoas a obtenção de capital para a entrada no promissor negócio das tropas. Os súditos da Coroa portuguesa que se envolveram no comércio de tropas e da erva-mate ficaram conhecidos como birivas. Esse foi o caso de Manoel Francisco Xavier, natural da Freguesia de Castro, então Província de São Paulo, que se instalou na região do Planalto em 1822, acompanhado do

\footnotetext{
As carnes passaram a ser aproveitadas em escala comercial a partir da produção das charqueadas, na década de 1780 .
} 
filho adolescente, Francisco, de escravos e índios ervateiros. Manoel explorou o produto nos ervais da Palmeira e, com os recursos obtidos, comprou uma tropa de mulas na Fronteira, que depois foi comercializada na feira de Sorocaba (Avila, 1996). Os números das exportações do Rio Grande do Sul, no mesmo ano, mostram a importância econômica da erva-mate nessa Província.

Em 1822, o Rio Grande exportou 797:183\$520rs em charque, 107:273\$600rs em couros, enquanto as vendas de erva-mate chegaram a 444:368\$960rs (CHAVES, 2004, p. 225). Ou seja, as exportações de erva-mate atingiram 50\% da receita obtida através do comércio dos dois principais produtos da pecuária bovina, números que mostram a importância econômica dessa atividade para o Rio Grande do Sul. No Paraná, foram largamente empregados os engenhos de moagem da erva-mate movidos pela força hidráulica, o que permitia uma melhor qualidade ao produto. $\mathrm{Na}$ década de 1870, a produção da Província do Paraná iniciou uma nova fase, através da difusão dos engenhos movidos a vapor. Os mecanismos de beneficiamento e o controle dos processos permitiram aos paranaenses a produção de uma erva-mate considerada de melhor qualidade, e de preço mais alto do que a produzida no Rio Grande do Sul ao longo do período imperial (ZARTH, 2002).

Os dados referentes às exportações de erva-mate do Rio Grande do Sul, ao longo do período imperial, mostram a importância do produto na economia local e o seu crescimento até a década de 1860. Esses números também confirmam a nossa hipótese de que a maior expansão dos ervateiros e negociantes do mate do Planalto ocorreu nas décadas de 1840 e 1850². Já nos anos 60 do século XIX, a saturação das primeiras áreas de exploração, bem como a exploração dos últimos mananciais nativos do mate levaram a uma retração da atividade. Na década de 1880, a produção de erva-mate teve uma queda acentuada, sendo reduzida à metade ou até a menos do volume das duas décadas anteriores. Isso se deve a dois motivos principais. Por um lado, a expansão da colonização sobre as áreas serranas levou à destruição de ervais para a abertura de lavouras, como foi o caso do vale do rio Pardo e Taquari; por outro, a exploração acentuada dos ervais pelos trabalhadores e negociantes do mate. As sucessivas colheitas, exigidas pelo próprio fechamento da fronteira agrária, obrigaram os ervateiros a extraírem o produto em intervalos menores, o que lentamente provocou a destruição das árvores ${ }^{3}$. Os próprios fazendeiros impulsionaram a exploração predatória do mate, e o preço da erva-mate oscilou entre $1 \$ 500$ rs e $3 \$ 000$ rs a arroba ao

2 Conforme a Revista do Arquivo Público do Rio Grande do Sul. Porto Alegre, n 08, 1922. Apud: ZARTH, 2002, op. Cit. pp. 225-226

3 Conforme mostram os registros paroquiais de terras e os processos de medições de Taquari e Rio Pardo, resultantes da aplicação da Lei de Terras de 1850. 
longo do período estudado (ZARTH, 2002). Em determinados períodos, com apenas três arrobas de erva-mate o fazendeiro poderia alcançar o mesmo valor que obteria com a venda de um novilho para a charqueada (CHRISTILLINO, 2010). Dessa forma, em um erval denso, em poucos hectares o proprietário ou arrematador poderia obter uma produção que rendia o mesmo valor de uma boiada enviada para a charqueada por um médio fazendeiro.

A erva-mate também despertou a atenção do Ministério dos Negócios Estrangeiros em 1871. Neste ano, o ministro Manuel Francisco Correia solicitou informações sobre as reservas do produto no território localizado a oeste das províncias de Santa Catarina e do Paraná e sobre o estágio e as possibilidades de exploração dessas riquezas pelos brasileiros. Essa missão foi confiada ao padre e historiador francês João Pedro Gay, visto que clérigo estava à frente da Paróquia de São Borja, no Rio Grande do Sul, e conhecia a região. Em 1871, o padre relatou em correspondência ao Presidente da Província, o senador Jerônimo Martiniano Siqueira Mello, as notícias obtidas sobre a região e os ervais nelas existentes. ${ }^{4}$ Segundo o pároco, depois da Guerra do Paraguai alguns argentinos estavam explorando madeiras e erva-mate nas "costas do rio Paraná", em pleno território brasileiro. Ainda segundo o padre, as informações que recebia em São Borja davam conta de que alguns moradores da Província de Corrientes estavam explorando aqueles ervais. Havia o projeto de construção de uma estrada na margem direita do rio Uruguai, em território argentino, para facilitar o escoamento da produção de erva-mate do país vizinho. Isso abriria espaço para uma exploração ainda maior dos argentinos sobre os ervais do Império. O Padre João Pedro afirmou que não havia o risco de os argentinos requererem o uti possidetis dos Campos de Palmas, nem dos ervais das serras próximas ao rio Paraná, uma vez que não estabeleceram guarnições ou povoados no local. No entanto, alertou sobre os prejuízos sofridos pelo Império com a exploração de seus ervais pelos ervateiros argentinos. O Padre João Pedro Gay alertou sobre o potencial econômico da região para os súditos do Império, uma vez que essas áreas poderiam proporcionar a ascensão econômica aos fazendeiros e negociantes, assim como ocorria nas regiões do Planalto e das Missões da Província do Rio Grande do Sul.

A extração do mate foi a principal fonte de receita da Câmara de Cruz Alta. Entre 1870 e 1873, os impostos sobre a erva-mate foram responsáveis por cerca da metade da arrecadação do município (ZARTH, 1997, p. 122). A arrecadação de impostos com a erva-mate também foi importante nos municípios de Taquari, Triunfo, Rio Pardo e Cachoeira, os quais abrangiam áreas serranas no período. A

4 Relatório do Padre Gay. Arquivo Padre Gay, lata 404, documento 37. Instituto Histórico e Geográfico Brasileiro- IHGB. 
Câmara de Cruz Alta cobrava uma taxa de $\$ 800$ réis por cada carreta abastecida de erva-mate, além de vender a própria licença de exploração dos ervais públicos. ${ }^{5} \mathrm{~A}$ expansão das atividades ervateiras interessava diretamente à Câmara pelo retorno em impostos obtidos com a exploração da erva-mate, bem como aos negociantes locais, os quais acumulavam fortuna com a sua comercialização. A "descoberta" e exploração de novos ervais eram fundamentais para a municipalidade e para os indivíduos envolvidos na atividade. A Câmara de Cruz Alta solicitou à presidência da província expedições de "reconhecimento e localização dos ervais" nas matas no interior do município.

Em 1857, o presidente da Província do Rio Grande do Sul, Patrício Correia da Câmara, atendendo a um pedido da Câmara de Cruz Alta solicitou ao Ministro do Império, o Marquês de Olinda, uma comissão de reconhecimento para a "descoberta" de um valioso erval no vale do Ijuí. Manuel Luís Osório, um dos mais renomados militares rio-grandenses-do-sul na época, foi encarregado de chefiar a expedição. Os tais ervais teriam sido "descobertos" por dois moradores da região das Missões que foram afugentados pelos indígenas que habitavam aquelas matas. A força comandada por Osório contou com um capitão, um tenente, um agrimensor, 27 soldados da Guarda Nacional e ainda com a participação do cacique Prudente e sete "índios mansos". A expedição levou meses em seu deslocamento até encontrar o dito erval (OSÓRIO, 1894). O longo período dessa incursão e o número de participantes mostram a importância desses novos ervais para a economia da Província. Em virtude do seu êxito, Manuel Luís Osório recebeu o título de Barão do Erval. A “descoberta” do erval consistiu em um fato mais importante na carreira do futuro General Osório do que a sua participação nas campanhas contra os governos de Oribe e Rosas, no início da década de 1850 .

As atas da Câmara de Cruz Alta mostram o impacto da descoberta desse novo erval na sociedade local. Em muitas reuniões eram discutidos os problemas relativos ao mate, à situação e ao reconhecimento dos ervais. Em 1860, a notícia de um novo erval na localidade do Campo Novo e o seu potencial de exploração esteve presente em parte significativa das reuniões dos vereadores. ${ }^{6} \mathrm{O}$ subdelegado do Distrito do Campo Novo, cap. João dos Santos Paiva ressaltou a importância desse erval para a "riqueza do Município". O subdelegado também solicitou a abertura de um "pique" em direção ao rio Uruguai para possibilitar a exportação da produção local ao mercado platino, especialmente a Buenos Aires. ${ }^{7}$

\footnotetext{
5 Conforme a ata da Câmara de Cruz Alta de 14 de fevereiro de 1851. Disponível no Arquivo Histórico da Câmara de Cruz Alta (AHCA).

6 Conforme atas da Câmara de Vereadores de Cruz Alta de 1860 (AHCA).

7 Conforme ata da Câmara de Vereadores de Cruz Alta, de 24 de janeiro de 1860 (AHCA).
} 
Os lucros propiciados pela erva-mate permitiram, num primeiro momento, que alguns homens de poucas posses ingressassem na pecuária e no comércio de tropas. Todavia, os ricos ervais encontrados no interior das matas do Planalto, somados à valorização do mate no mercado platino, incentivaram os fazendeiros, especialmente a partir da década de 1840, a explorar essa atividade. A erva-mate redirecionou a produção local e a própria ocupação do Planalto e das Missões. Os registros paroquiais de terras de Cruz Alta mostram que os fazendeiros estavam se apropriando de largas extensões de terras florestais no município, exatamente nas áreas de ervais. Os criadores geralmente declaravam as suas áreas de campo, e depois registravam mais uma "posse de matos obtida por legítima ocupação". Dependendo do local, com alguns hectares de erva-mate era possível obter o mesmo capital propiciado por uma extensa área de campo.

Os maiores fazendeiros do Planalto ingressaram na extração da erva-mate. Na década de 1850, o ten.-cel. Joaquim Thomaz da Silva Prado, o segundo maior proprietário de terras de Cruz Alta, declarou, nos registros paroquiais, 18 léguas de campo no Distrito da Palmeira. ${ }^{9}$ Além desses vastos campos (mais de 78 mil hectares), Silva Prado ainda declarou, em nome de seus filhos, mais 10 áreas de "posses de matos" na serra do Ijuí, uma região rica em ervais. As "posses de matos" da família Silva Prado teriam a extensão de quase três léguas de área (mais de 12.500 hectares) nas bordas das suas duas fazendas. ${ }^{10} \mathrm{O}$ Barão do Ibicuí, o terceiro maior proprietário de terras do município de Cruz Alta nesse período, além de registrar a posse de oito léguas de campo (mais de 34 mil hectares), ${ }^{11}$ declarou-se proprietário de uma área de meia légua de "terras lavradias" na Palmeira, distrito de Santo Ângelo. Essa posse de mais de dois mil hectares estava localizada ao sul da fazenda das Brancas, na Serra do Ijuí. ${ }^{12}$ Essa região era rica em ervais, e os processos de legitimação do Barão mostram indícios da sua exploração pelo estancieiro, ${ }^{13}$ mas não se restringiam à posse de "terras de agricultura".

\section{OS TRABALHADORES DO MATE}

Um grande número de ervateiros, como eram conhecidos os homens que trabalhavam na extração do mate, já exploravam a mesma área no Distrito

\footnotetext{
Conforme os registros paroquiais de terras da Freguesia de Cruz Alta. Arquivo Histórico do Rio Grande do Sul (AHRS).

9 Conforme os registros paroquiais de terras da Freguesia de Cruz Alta, n 09 e 11 (APERS).

10 Conforme os registros paroquiais de terras da Freguesia de Cruz Alta, n $13 ; 14 ; 18 ; 19 ; 20 ; 21$; $22 ; 23 ; 24 ; 25$ (APERS).

11 Registros paroquiais de terras da Freguesia de Cruz Alta, n 492, 496 e 512. APERS.

12 Registro paroquial de terras da Freguesia de Cruz Alta, n ${ }^{\circ}$ 509. APERS.

13 Conforme os autos de legitimação de terras, $\mathrm{n}^{\circ}$ 194, 195, 196, 197, 198 e 737 (AHRS).
} 
da Palmeira. Estes formaram um grupo social extenso na Província do Rio Grande do Sul, conforme observado na documentação do período. ${ }^{14}$ Linhares (1969) afirma que na região das Missões havia cerca de seis mil trabalhadores envolvidos na colheita da erva-mate no ano de 1856 (LINHARES, 1969, p. 105). Os ervateiros constituíram o universo de homens pobres dedicados à extração da erva-mate, sem posse formal de suas terras, na maioria dos casos. A sua origem social era heterogênea, composta por agricultores e agregados que migravam em busca de alternativas à pressão fundiária das áreas próximas às vilas e das lavouras de meação das fazendas locais, por escravos fugitivos e por um grande número de foragidos da justiça.

Os ervais se consagraram como um local de refúgio. Durante a Farroupilha, por exemplo, muitos combatentes farrapos retiraram-se para os ervais de Taquari após o c de Santo Amaro em 1837. Além disso, os ervateiros também foram marcados pela diversidade étnica. Popularmente conhecidos como caboclos, este grupo foi caracterizado pelo encontro entre o negro, o branco e o indígena. Uma boa parte dos homens que migraram para os ervais constituiu família com as "bugras mansas".

Muitos fazendeiros empregaram os ervateiros nas suas terras, pagando a eles dois terços do total de erva-mate colhida (CHRISTILLINO, 2004). No entanto, a grande maioria dos ervais encontrava-se em terras públicas. Linhares (1969) afirma que cada peão recebia, em média, 4\$000rs por cada jornada diária de trabalho nos ervais rio-grandenses-do-sul, um valor que consideramos alto para o período, pois foi a remuneração que os trabalhadores campeiros receberam somente em 1910 (MAESTRI, 2008). Na década de 1850, os fiscais dos ervais de Santo Ângelo, de Soledade e da Palmeira recebiam a gratificação anual de $240 \$ 000$ rs. Já os guardas municipais, encarregados de auxiliar os fiscais, recebiam apenas $100 \$ 000$ rs anuais. ${ }^{15}$ Os trabalhadores dos ervais geralmente dedicavam-se à atividade nos meses de outono e inverno. No verão e na primavera trabalhavam em suas lavouras de "subsistência", cujos roçados também abasteciam o mercado local.

As duas obras clássicas sobre o grupo de "agricultores pobres nacionais" consagraram a visão da sua desintegração da vida econômica e política da sociedade brasileira no século XIX e no início do século XX. Maria Sylvia de Carvalho Franco (1983) analisou este grupo social no século XIX, e defende que a violência cotidiana entre esses homens era o subterfúgio para a falta de mobilidade social deste segmento. A escravidão teria deixado os homens livres e

14 Processos de legitimação de terras, correspondência das câmaras de vereadores, processos crimes, relatórios de presidentes de província e memórias de época.

15 Atas da Câmara de Cruz Alta da década de 1850 (AHCA). 
pobres "sem razão de ser" naquela sociedade. Antonio Cândido (1964) estudou o "caipira" paulista nas décadas de 1940 e 1950. Na sua concepção, os homens pobres do campo tinham uma cultura pobre, a qual "[...] não foi feita para o progresso: a sua mudança é o seu fim [...]" (CANDIDO, 1964, p. 82). A falta de estímulo e de técnicas produtivas teria causado o seu "desapego ao trabalho".

Martins (2009) defende que o avanço da fronteira interna tem um caráter de sacrifício, pois é na expansão da fronteira econômica que o outro é degradado, isso para assegurar a existência de quem domina. $\mathrm{O}$ autor busca desconstruir o mito do pioneiro, mostrando o aspecto trágico da fronteira que se afirma a partir da destruição de grupos pré-estabelecidos nas "novas áreas", mas não totalmente integrados ao capitalismo, quando são recriadas formas arcaicas de dominação e de reprodução ampliada do capital, como a escravidão. Martins (2009) distingue o avanço da fronteira em duas frentes. A frente pioneira define-se economicamente pela exploração capitalista da terra, enquanto a frente de expansão constitui a etapa de ocupação entre a primeira e a frente demográfica, cujo grupo mais representativo seria o indígena. $\mathrm{Na}$ visão do autor, ambas constituem momentos históricos distintos e combinados de ocupação da fronteira, visto que a frente de expansão é o momento em que a vida econômica não está estruturada na relação com o mercado, mas não pode ser considerada uma economia natural, na medida em que fornece produtos para a comercialização. Essa seria a economia dos excedentes, tendo como principal objetivo a subsistência, seguido da troca dos seus produtos por outros em circulação no mercado. Entretanto, esses também não poderiam ser enquadrados na fronteira econômica, em função da entrada de excedentes demográficos, que não poderiam ser englobados por essa fronteira. Assim, a frente de expansão estaria interligada ao capitalismo, ao oferecer mão de obra e oportunidades de abertura de espaço às futuras ocupações da frente pioneira. ${ }^{16}$

A discussão de José de Souza Martins (2009) contribuiu para os estudos sobre a fronteira no Brasil, especialmente ao desenvolver uma análise sociológica sobre uma temática que vinha recebendo destaque somente da antropologia. Em seu trabalho, o autor juntou o "mundo do posseiro" numa única singularidade. A fronteira de expansão englobou um grupo social complexo, com níveis diversos de integração ao mercado e em meio a processos sociais variados. A sua abordagem sobre a fronteira de expansão não nos permite enquadrar a experiência histórica dos homens pobres inseridos na atividade de extração da erva-mate no Rio Grande do Sul, pois no século XIX não houve uma separação assim tão nítida entre este grupo e aqueles que praticaram a "agricultura pioneira".

16 Martins constrói seu conceito a partir da realidade da Amazônia no século XX, mostrando que o capitalismo provoca a reprodução de relações não capitalistas de trabalho, como é o caso do escravismo. 
No caso do Rio Grande do Sul, no século XIX, a economia praticada pela frente pioneira, que tem o tipo mais representativo na figura do imigrante, e pela de frente expansão, que seria a dos ervateiros não constituiu, na maioria dos casos, realidades distintas. Nem as atividades das colônias imigrantes, nem mesmo a dos fazendeiros poderiam ser totalmente vinculadas ao mercado, assim como a "economia do excedente" da frente de expansão não estaria assim tão distante dele. Alguns ervateiros estavam integrados ao mercado de tal maneira, que conseguiram acumular fortuna. Outros posseiros arranchados no interior das matas também vendiam seus produtos regularmente no comércio local. Hebe Maria Mattos (1986) destaca a importância e a abrangência desse grupo em meio às lavouras escravistas no Sudeste, na segunda metade do XIX. Segundo a autora:

Não se trata, no entanto, de uma área de economia natural, pois dela saem regularmente produtos que assumem valor de troca no mercado, completando o processo de reprodução social de seus participantes. No período escravista, o avanço da plantation, se, por um lado, determinou o desenraizamento histórico do pequeno produtor rural no espaço sóciohistórico brasileiro, por outro, não chegou a desenvolver mecanismos suficientemente poderosos para impossibilitar-lhes a existência (MAT'TOS, 1986, p. 15).

Os ervateiros e pequenos posseiros do Rio Grande do Sul estavam integrados, mesmo que sazonalmente, ao comércio local. Dessa forma, não é possível enquadrálos numa frente de expansão, isolando-os da realidade dos colonos imigrantes. Estes últimos realmente estavam mais integrados ao mercado provincial, em função das dívidas assumidas na aquisição dos seus lotes de terra (CUNHA, 1991). Essa visão nega o pioneirismo de muitos grupos que seriam enquadrados, a partir da concepção de Martins (2009), na dita frente de expansão, como foi o caso daqueles que trabalhavam na extração da erva-mate e nas lavouras de alimentos. É importante levar em conta que, nas próprias colônias alemãs, os colonos produziam uma boa parte para a sua subsistência e muitas vezes apenas os excedentes eram levados ao comércio. Por outro lado, a propriedade da terra constituiu um longo processo de transição ao longo do XIX, dessa forma, em geral não é possível diferenciar as pequenas colônias dos imigrantes das posses dos ervateiros. Os trabalhadores que atuaram na cadeia de exploração da erva-mate não poderiam ser enquadrados unicamente numa frente de expansão, à margem do mercado, quando eram responsáveis pelo segundo produto mais importante da economia da Província do Rio Grande do Sul durante boa parte do século XIX. Paulo Zarth (1997), em seu trabalho pioneiro sobre os "lavradores nacionais" (ervateiros), mostrou que o mesmo grupo não estava isolado naquele contexto e tampouco afastado dos mercados. Neste sentido, este autor defende que esses trabalhadores poderiam, em 
sua grande maioria, ser enquadrados como camponeses.

Em alguns casos os ervateiros representaram uma ameaça aos interesses dos fazendeiros e negociantes de erva-mate. Ainda em 1849, a Câmara de Cruz Alta tomou algumas medidas para impedir a destruição dos ervais do município, os mais importantes da Província. ${ }^{17}$ As colheitas predatórias da erva-mate estavam aniquilando as árvores de mate e, por vezes, levaram à destruição dos ervais. A Câmara de Cruz Alta buscou meios para impedir a ruína da sua mais importante fonte de renda, através do aumento de impostos e da fiscalização. Uma arrecadação maior permitiria a melhor remuneração dos fiscais e guardas que atuavam nos ervais, de modo a estimulá-los a aplicar sanções do Código de Postura municipal e de outras medidas tomadas pela Câmara para regrar a exploração dos ervais públicos. Porém, essas medidas não impediram a apropriação de vastas extensões de ervais pelos fazendeiros do Planalto, conforme mostram os registros paroquiais de terras. Essas áreas não poderiam ser incorporadas aos domínios dos fazendeiros, conforme previa a Lei de Terras, uma vez que somente as atividades agrícolas e pecuárias confeririam legitimidade de posse, e o mesmo direito não era estendido às áreas de extrativismo. Ainda assim, a destruição dos ervais de Cruz Alta era atribuída à "posse coletiva".

É ao principio da propriedade comum que nos devemos a destruição de todos os magnificos hervaes deste municipio, e por consequencia a expantosa diminuição deste produto que tende a desaparecer d'entre nós, se medidas muito energicas não forem tomadas por esta Camara para abster a sua total destruição, passando os hervaes ao dominio privado. ${ }^{18}$

Nesse trecho da ata da Câmara de Cruz Alta, os vereadores mostram a sua visão sobre o problema. As causas da destruição dos ervais deviam-se ao fato de uma parte significativa desses ser pública e, assim, a população tinha livre acesso a eles. A solução para a sua preservação estaria na transferência dos ervais para o domínio privado. Dessa forma, as apropriações abusivas dos fazendeiros estariam em direção à "solução" e à preservação de tais áreas. Isso, quando alguns fazendeiros ocupavam cadeiras no legislativo municipal de Cruz Alta ou então eram representados por integrantes das suas redes de relações sociais.

Em 1856, na região das Missões, principalmente no Distrito da Palmeira, havia mais de seis mil homens trabalhando nos ervais (LINHARES, 1969). Nesse período, as "invasões" às matas públicas, ricas em mate, fugiam ao controle da Câmara de Cruz Alta. No plano jurídico, a Lei de Terras de 1850 transformou, desde então, o pequeno posseiro em invasor. As câmaras municipais se basearam

17 Ata da Câmara de Cruz Alta de 12 de junho de 1849 (AHCA).

18 Ata da Câmara de Cruz Alta de 28 de abril de 1868 (AHCA). 
nessa lei para formular artigos adicionais aos seus códigos de postura, a fim de regrar o uso dos ervais públicos e imputar penalidades aos infratores. A Câmara de Cruz Alta foi pioneira em anexar artigos que tratassem da questão dos ervais. ${ }^{19}$

Em 1867, o presidente Francisco Homem de Melo destacou em seu relatório os problemas em torno da produção da erva mate (MELLO, 1867). $\mathrm{O}$ presidente determinou às câmaras que dessem atenção ao assunto e que formulassem normas municipais em relação à qualidade da erva-mate e à destruição dos ervais, em conformidade com o que fizera a Câmara Municipal de Cruz Alta. Uma boa parte dos municípios onde havia florestas ricas em mate atendeu aos sucessivos pedidos dos presidentes provinciais e formulou adendos aos seus códigos de postura. Santo Antonio da Patrulha e Taquari tiveram alterações aprovadas no início da década de 1870. Neste último município, os artigos complementares ao seu código de postura foram apresentados em $1873 .^{20}$

Taquari englobava uma considerável extensão de áreas serranas ricas em ervais, e a sua conservação interessava tanto à municipalidade quanto aos fazendeiros e negociantes de erva-mate. Os adendos ao seu código de postura foram apresentados com o objetivo principal de garantir a qualidade do produto. No entanto, observa-se que o seu principal propósito foi coibir a ação dos ervateiros pobres sobre os estoques de mate existentes nas áreas públicas. Dos nove artigos apresentados, apenas dois se referiam à qualidade do produto, os outros sete diziam respeito às restrições na extração e abertura de roçados no interior dos ervais. Estes últimos estavam diretamente relacionados às atividades dos ervateiros, que permaneceram sujeitos a multas e à prisão. $\mathrm{Na}$ verdade, os maiores responsáveis pela destruição dos ervais em Taquari foram os colonizadores, que lotearam áreas públicas e venderam aos imigrantes. Estes, por sua vez, derrubavam as matas ricas em mate para a formação de lavouras. Nenhum colonizador foi multado ou denunciado pelos fiscais dos ervais públicos.

Os códigos de postura dos municípios, ao criarem mecanismos de preservação dos ervais contra a ação dos ervateiros e pequenos posseiros, mostram o interesse cada vez maior dos fazendeiros e dos negociantes de ervamate na extração do produto nas matas do Planalto e da região serrana. Uma árvore de mate adulta poderia render até 50 ou 60 quilos de ramos de mate para o beneficiamento (LINHARES, 1969). Com isso, dependendo do erval, apenas duas árvores poderiam render pelo menos uma arroba de erva-mate pré-moída

19 Mas as alterações no código de posturas municipais de Cruz Alta não foram encontradas em nossa pesquisa. O presidente provincial Homem de Mello citou o mesmo código de postura em 1867, alegando que as demais câmaras deveriam seguir o seu exemplo. Entretanto, na correspondência da Câmara e nas atas das reuniões dos vereadores não constam esses artigos ou mesmo o novo código.

20 Correspondência da Câmara Municipal de Taquari de 1873, nº 17 (AHRS). 
e desidratada, pronta para o comércio nos engenhos de processamento ou para venda final. Um erval "rico" poderia conter até 100 árvores de Ilex paraguariensis por hectare, o que renderia mais de 50 arrobas de erva-mate beneficiada que, negociadas por um valor entre $1 \$ 500$ rs e $3 \$ 000$ rs a arroba, poderiam render pelo menos o mesmo capital obtido com a venda de 15 novilhos para a charqueada. Nessa base, em 15 ou 20 hectares de um erval "rico", o produtor poderia obter uma renda aproximada a que um estancieiro alcançava numa légua de campo. ${ }^{21}$ O mate propiciava uma colheita a cada quatro ou cinco anos, e sua incidência geralmente não era de forma tão adensada quanto a anteriormente descrita. Todavia, esses dados mostram que os ervais "ricos" poderiam proporcionar, em poucos hectares, uma renda superior àquela obtida numa fazenda de gado.

A década de 1860 também foi marcada pela crise na pecuária muar. Cruz Alta era um produtor tradicional de mulas - o maior da Província do Rio Grande do Sul. Em 1800, a Feira de Sorocaba recebeu anualmente cerca de 20 mil mulas do Sul; em 1850, foram 50 mil; em 1865, foram 100 mil muares, mas entre 1875 e 1890, essa média caiu para apenas 12 mil mulas por ano (COSTA, 1982). Em 1863, o Barão de Ornano registrou que a produção de mulas encontrava-se em franca ruína na Província. Segundo ele, na década de 1850 pagava-se até 30\$000rs por uma mula no Rio Grande do Sul, mas em 1863 o seu valor não ultrapassou os 5\$000rs, e ainda assim era difícil encontrar compradores. ${ }^{22} \mathrm{O}$ relatório do Cônsul Francês em Porto Alegre mostra que os pecuaristas dedicados à produção de mulas tiveram um grande prejuízo. ${ }^{23}$ Logo, esses criadores teriam que procurar outras alternativas, e a erva-mate foi a atividade que proporcionou maiores lucros no período.

Mesmo a agricultura, cuja produção era ainda incipiente no Planalto, no período entre 1850 a 1880, apresentava um baixo rendimento e seus preços não eram tão compensadores quanto os da erva-mate. Em 1867, a saca de feijão exportada do Rio Grande do Sul alcançou $4 \$ 500$ rs e a saca de milho $2 \$ 800$ rs, ${ }^{24}$

21 Um estancieiro poderia ter em média até mil cabeças de gado numa légua de campo, do qual obteria cerca de 100 cabeças para comercializar anualmente. O preço médio do novilho oscilou entre $8 \$ 000$ réis e $10 \$ 000$ réis na década de 1870 , portanto 100 cabeças atingiriam um valor em torno de $800 \$ 000$ réis e 1:000\$000rs. Em determinados períodos esse valor poderia ser obtido com um volume inferior a 400 arrobas de erva-mate (CHRISTILLINO, 2010).

22 O Barão de Ornano atribuía a decadência do mercado de mulas às melhorias nas estradas no Sudeste e à introdução de estradas de ferro, o que facilitou o transporte nas regiões cafeeiras e dispensou, em parte, o tráfego muar. Como as mulas eram amplamente utilizadas no transporte de cargas em todo o Brasil naquele momento, e a economia do Sudeste não se limitava à produção cafeeira. É bem possível que a ruína do mercado de tropas muares do Sul também esteja vinculada à superprodução local ou também à concorrência de outras áreas, inclusive do próprio Sudeste (ORNANO, 1996).

23 Em parte, a diminuição da produção muar se deve à valorização do gado bovino no mercado provincial. Seus preços eram mais atrativos, diante da desvalorização das mulas, além disso, o ciclo de reprodução dos bovinos era menor (CHRISTILLINO, 2010).

24 Conforme Revista do Arquivo Público do Rio grande do Sul, no 08, 1922 (apud ZARTH, 2002). 
valores referentes ao preço final desses produtos registrados nas alfândegas. Sabemos que entre o agricultor e o porto era percorrido um longo caminho, em que o transporte e os atravessadores tomavam a maior parte dos valores obtidos com esses produtos. No mesmo período, o preço da arroba da erva-mate variava entre $1 \$ 500$ rs e $3 \$ 000$ rs, portanto, até mesmo por uma questão de mão-de-obra, a erva-mate foi bem mais lucrativa do que a agricultura, o que incentivou os fazendeiros a se apropriarem de ervais, a maioria absoluta em terras públicas.

Os engenhos para o beneficiamento da erva-mate também permitiram o desenvolvimento de algumas serrarias. Nos registros paroquiais de terras de Cruz Alta há nove referências a esses estabelecimentos. Boaventura Soares da Silva declarou possuir "uma propriedade com casas, engenho de serrar madeiras, matos, potreiros de pequenos campos e grandes capoeiras" no Pirapó, região próxima à foz do rio Ijuí, nas águas do Uruguai, com a extensão de uma légua e meia. ${ }^{25}$ Esses locais mostram, por um lado, a progressiva diversificação da economia local, mas, por outro, chama a atenção para a ligação dos povoados missioneiros como Prata. O rio Uruguai foi a principal via de escoamento da erva-mate e de outros produtos daquelas localidades. Como a serraria de Boaventura Souza da Silva estava localizada próxima ao rio Uruguai, sua produção e as de outras propriedades na mesma região provavelmente esteve direcionada aos mercados da Argentina e da República Oriental.

\section{AS DISPUTAS ENTRE FAZENDEIROS E ERVATEIROS}

No Planalto, a grande maioria das terras era fruto de posse e uma boa parte era resultado da grilagem. Os fazendeiros dessa região, além de efetuarem "posses suspeitas", também enfrentavam a resistência dos ervateiros e pequenos posseiros à expropriação da terra e dos ervais. Os processos de legitimação também resultaram da ameaça à ocupação de propriedade. Os fazendeiros recorriam a Lei de Terras sempre que esta pudesse beneficiá-los. Foi o caso dos irmãos Rodrigues Fonseca, no Distrito de Santo Ângelo em Cruz Alta.

Os irmãos Rodrigues Fonseca eram paulistas e teriam se instalado na região das Missões em meados da década de 1830, quando João Rodrigues da Fonseca trabalhou como capataz na fazenda Monte Alvão, de propriedade do Barão de Ibicuí. ${ }^{26}$ João e seus irmãos provavelmente mudaram para o Rio Grande do Sul por meio do trabalho nas tropas organizadas pelo Barão do Ibicuí, o guarda-mor Francisco Paula e Silva, e do barão de Antonina, o ten.-cel. João da

\footnotetext{
25 Registro paroquial de terras da Freguesia de Cruz Alta nº 667 (APERS).

26 Auto de medição nº 198 (AHRS).
} 
Silva Machado. Em 1835, quando os irmãos Rodrigues teriam chegado ao Sul, eles ainda eram jovens. João tinha 21 anos, Antonio com 20 anos e Luciano tinha apenas 14 anos. Além deles, a documentação analisada ainda faz referência a mais três irmãos: Ângelo, Francisco e José Rodrigues da Fonseca. Num primeiro momento, trabalharam na fazenda do Barão do Ibicuí e, em seguida, apossaramse de terras nas bordas dos campos do capitão-mor. As áreas de matas e alguns campos do Planalto e das Missões foram os últimos espaços que ocuparam na Província do Rio Grande do Sul, em função da resistência das tribos caingangues e guaranis à ocupação dos seus territórios, o que retardou a posse definitiva. Os processos de legitimação e os registros paroquiais de terras apontam que a ocupação dos campos localizados próximos à Serra do Ijuí, no Distrito de Santo Ângelo, iniciou na década de 1830. As áreas florestais da região, ricas em ervamate, foram apossadas posteriormente. A própria expedição de reconhecimento a um erval no vale do Ijuí, em 1857, comandada pelo então ten.-cel. do Exército Manuel Luís Osório, onde alguns ervateiros foram "corridos pelos índios", comprova a ocupação tardia dessas matas em relação às áreas de campo do mesmo distrito. A valorização da erva-mate foi um incentivo à ocupação das áreas florestais do Planalto e das Missões.

A trajetória dos irmãos Fonseca mostra que muitos milicianos, ao ingressarem nas tropas ou nas redes de relações sociais de alguns chefes da Guarda Nacional, puderam obter vantagens na apropriação de terras. João Rodrigues da Fonseca e Antonio Rodrigues da Fonseca obtiveram a patente de tenente no regimento comandado pelo Barão do Ibicuí. Luciano e José Rodrigues da Fonseca não aparecem nos processos enquanto ocupantes de postos na milícia. Ainda assim, a participação nas tropas comandadas pelo Barão, no momento da ocupação dos campos do Distrito de Santo Ângelo, garantiu-lhes o acesso à terra na região. As apropriações dos irmãos Fonseca mostram a importância da patente no acesso a terras, mesmo que por meio de posse. João Rodrigues da Fonseca, que ocupou o posto de tenente, apossou-se de 9.400 hectares. José Rodrigues da Fonseca, também integrante da Guarda Nacional, ocupou 8.258 hectares, enquanto Luciano Rodrigues da Fonseca, que era mais novo e não obteve patente na Milícia, apossou-se de 6.886 hectares, todas localizadas nas bordas das fazendas do Barão do Ibicuí. Isso mostra que, na ocupação do Planalto e das Missões, a patente militar e miliciana era importante para o acesso a terras, principalmente em função da "ratificação" ou permissão dos chefes militares.

Seis integrantes da família Rodrigues Fonseca possuíam terras no Distrito de Santo Ângelo, ${ }^{27}$ mas somente três deles legitimaram as suas posses: João, José

7 Francisco Rodrigues da Fonseca declarou duas áreas de terras que somavam mais de 7.600 
e Luciano Rodrigues da Fonseca. Esse fato mostra que os fazendeiros somente encaminharam processos de legitimação quando a sua posse estava sendo contestada por outros posseiros ou ervateiros. Já as áreas de "posses mansas e pacíficas" dos outros integrantes da família Fonseca não foram legitimadas. João, José e Luciano Rodrigues da Fonseca legitimaram 24.644 hectares de terras no Distrito de Santo Ângelo, na Serra do Ijuí.

Os processos de legitimação expressam as disputas existentes em torno da apropriação fundiária. As ações eram caras e demoradas, e o seu encaminhamento ocorria geralmente diante da ameaça de outros confrontante que possuíam o mesmo poder econômico ou prestígio político e social. Esses processos revelam a dinâmica política da afirmação de propriedade e mostram outra face da aplicação da Lei de Terras de 1850, ainda não explorada pela historiografia: a contribuição da sua aplicação no processo de centralização política do Governo Imperial. O Decreto $n^{\circ} 1.318$, de 30 de janeiro de 1854, que regulamentou a aplicação da Lei, estabeleceu que as ações de legitimação e revalidação de terras, encaminhadas após o período das declarações paroquiais de terras (1854-1857) tramitariam nas repartições especiais de terras públicas. Esses órgãos estavam subordinados às secretarias das presidências provinciais, e o julgamento sobre os processos caberia ao chefe do executivo provincial e não a um magistrado. A aprovação dos autos dependeria da "avaliação" do presidente provincial sobre os processos. Estes foram encaminhados diante de litígios, e sua aprovação dependeu, em boa parte dos casos analisados, do grau de influência política do legitimante com a presidência da província. As ações analisadas, nos municípios de Taquari e de Cruz Alta revelam a intensidade das disputas em torno da apropriação territorial e os enfrentamentos entre os membros da elite no apossamento das terras devolutas. Umprocesso de legitimação muitas vezeserafruto do enfrentamento de duas famílias que ocupavam altas patentes na Guarda Nacional. Essas disputas equilibradas exigiam uma maior aproximação dos fazendeiros com a presidência da província. Além disso, os dispositivos da Lei, ao proibirem a posse após 1850, e exigirem a ocupação efetiva das áreas apropriadas para a sua titulação, ameaçaram o direito de acesso dos mesmos fazendeiros. Esse contexto exigiu dos posseiros uma longa negociação política com a Coroa (CHRISTILLINO, 2012, p. 223-245).

Em Cruz Alta, foram encaminhados 86 processos de legitimação para a obtenção do título de propriedade, dos quais 48 se referiam à posse em terras

\footnotetext{
hectares. Ângelo Rodrigues da Fonseca registrou meia légua de campo no Distrito da Vila de Cruz Alta e aparece como confrontante de uma área de matos na Serra do Ijuí. Esse era o mesmo local em que Porfírio Rodrigues da Fonseca aparece como vizinho de uma posse em terras de matas. Esses três posseiros não efetuaram processos de legitimação de suas terras. Conforme os registros paroquiais de terras da Freguesia de Cruz Alta no 44; 56; 57; 252; 262; 278. APERS.
} 
de matas. Essas 48 áreas florestais legitimadas somaram 65.098 hectares, uma média de 1.356 hectares para cada posseiro, um dado que mostra a intensidade da grilagem nessa região. Nossa hipótese, com base na pesquisa dos registros paroquiais de terras, nos processos de legitimações e nas fontes sobre as colônias imigrantes, é de que uma unidade produtiva baseada na agricultura poderia atingir, numa expectativa bastante otimista, 300 hectares (CHRISTILLINO, 2010), no período de 1850 a 1880 no Planalto do Rio Grande do Sul. Nesta região, no caso do agricultor que contava com o maior plantel escravo empregado na lavoura, tinha uma propriedade que não ultrapassava 150 hectares! Os ervais constituíam uma importante fonte de lucros para os fazendeiros do Planalto e das Missões, em alguns casos proporcionando lucros não alcançados na pecuária, fato que levou os fazendeiros a se apropriarem da maior extensão possível deste importante recurso natural. Ato este proscrito pela Lei de Terras de 1850, por se tratar de uma atividade extrativa e que não propiciava "cultura efetiva e morada habitual".

Os registros paroquiais de terras demostram a intensidade das apropriações dos ervais pelos fazendeiros. Entre as declarações que citaram a extensão da área em Cruz Alta, 63,48\% registraram terras na faixa entre 1.001 e 5.000 hectares. Grande parte delas se refere a posses em terras florestais ricas em ervais, declaradas principalmente no tamanho de um quarto de légua (1.089 hectares) e de meia légua (2.178 hectares). Essas áreas registradas dificilmente seriam totalmente ocupadas para agricultura. Por isso, o próprio percentual de extensão declarado nos registros paroquiais entre 1.001 e 5.000 hectares mostra a intensidade da grilagem no município de Cruz Alta.

A erva-mate também foi uma importante fonte de lucros para os negociantes. Nesse momento, o gado do Planalto era negociado com os tropeiros, geralmente de outras regiões, com charqueadores estabelecidos nas margens do Jacuí (Rio Pardo, Cachoeira do Sul e São Jerônimo), no sul da Província (Rio Grande e Pelotas) e na Campanha. Dessa forma, a erva-mate abriu um grande espaço para a atuação dos negociantes do Planalto. O produto garantiu a acumulação de capital nas mãos de muitos "birivas", permitindo o seu ingresso no comércio de tropas. Também possibilitou que alguns pequenos negociantes ou arrematantes de ervais estabelecessem casas de comércio nas suas proximidades e formassem fortuna, como foi o caso de Joaquim Pereira da Motta e de João José Veau. Linhares (1969) também relatou os altos lucros obtidos pelos negociantes da erva-mate no Paraná, citando o caso de um deles que, mesmo tendo utilizado um empréstimo para obter o capital de giro, conseguiu um lucro de $200 \%$ em um ano de atividade (LINHARES, 1969). 
A erva-mate do Planalto e das Missões era vendida principalmente em duas praças comerciais. A primeira era nas casas de negócios nas margens do rio Uruguai, e as mais importantes localizavam-se em Itaqui. Desses entrepostos, a erva-mate era exportada para o Prata. A segunda praça comercial era Rio Pardo, para onde era enviada a produção do Distrito do Botucaraí. A cidade de Rio Pardo estava estabelecida no trecho navegável do Jacuí e o acesso terrestre se dava por duas estradas na Serra Geral: a de Santa Cruz e a do Botucaraí. A erva-mate era transportada por embarcações de Rio Pardo até Porto Alegre e Rio Grande, de onde era distribuída ao interior da Província e também exportada. Ave-Lallemant visitou o Rio Grande do Sul em 1858 e registrou que em Rio Pardo havia um engenho capaz de beneficiar até 100 arrobas de erva-mate por dia. O médico alemão também destacou o caso de uma "pequena firma francesa" em Itaqui que exportava anualmente quatro mil arrobas do produto (LINHARES, 1969). Os processos de legitimação de terras e os registros de transmissão de tabelionato de Cruz Alta mostram a disseminação dos engenhos de moagem de erva-mate nas regiões do Planalto e da Serra. Esses dados confirmam a existência de um importante complexo ervateiro no Rio Grande do Sul em meados do XIX.

\section{CONSIDERAÇÕES FINAIS}

No período de 1850 a 1880, os altos lucros com a exploração da erva-mate estimularam a apropriação de terras, sendo que o mate foi a segunda riqueza mais importante da Província. A análise da estrutura produtiva dos estancieiros na década de1850 revelou a baixa lucratividade apresentada pelos rebanhos, cujos preços não cresceram na mesma proporção dos valores do hectare de terra. No caso de Cruz Alta, o número de estancieiros que enfrentavam problemas financeiros foi ainda maior. Esse contexto levou os criadores a se apossar das terras de ervais, pois o mate exigia baixos investimentos e proporcionava bons ganhos. Nas áreas mais ricas em matéria-prima, poucos hectares poderiam render um lucro maior do que aquele obtido em uma légua de campo pela pecuária. Essa conjuntura explica a rápida apropriação dos ervais do Planalto pelos fazendeiros, expansão esta baseada na grilagem de terras públicas.

\section{REFERÊNCIAS}

BANDEIRA, L. A. M. O expansionismo brasileiro e a formação dos estados na Bacia do Prata: da colonização à Guerra da Tríplice Aliança. Brasília, DF: EDUnB; Revan, 1985. 
CANDIDO, A. Os parceiros do Rio Bonito: estudo sobre o caipira paulista e a transformação dos seus meios de vida. Rio de Janeiro: José Olympio, 1964. CHAVES, A. G. Memórias ecônomo-políticas sobre a administração pública do Brasil. 4. ed. São Leopoldo: EDUnisinos/Copesul, 2004.

CHRISTILLINO, C. L. Estranhos em seu próprio chão: o processo de apropriações e expropriações de terras na Província de São Pedro do Rio Grande do Sul (o Vale do Taquari no período de 1840-1889). 2004. Dissertação (Mestrado em História) - Universidade Vale do Rio dos Sinos, São Leopoldo, 2004.

Litígios ao sul do Império: a Lei de Terras e a consolidação política da Coroa no Rio Grande do Sul (1850-1880). 2010. Tese (Doutorado em História) - Universidade Federal Fluminense, Niterói, 2010.

Sob a pena presidencial: a Lei de Terras de 1850 no Rio Grande do Sul e a negociação política. Revista Tempo, v. 16, p. 223-245, 2012.

COSTA, L. O continente das Lagens. Florianópolis: FCC, 1982.

CUNHA, J. L. Os colonos alemães e a fumicultura: Santa Cruz do Sul, Rio Grande do Sul 1849-1881. Santa Cruz do Sul: EDFISC, 1991.

D'AVILA, N. E. Passo Fundo: terra de passagem. Passo Fundo: Aldeia Sul, 1996.

D'ORNANO, P. B. Um barão na província. Apêndice ao Relatório Geral, 1863. Tradução Fúlvia Moretto. Porto Alegre: EDIPUCRS/INL, 1996.

FRANCO, M. S. de C. Homens livres na ordem escravocrata. São Paulo: Kairós, 1983.

GARAVAGLIA, J. C. Mercado interno y economia colonial: três siglos de historia de la yerba mate. 2. ed. Rosario: Prohistoria, 2008.

LINHARES, T. História econômica do mate. Rio de Janeiro: José Olympio, 1969.

MACHADO, P. P. Lideranças do contestado: a formação e atuação das chefias caboclas (1912-1916). Campinas: EDUnicamp, 2004.

MAESTRI, M. (Org.). O negro e o gaúcho: estâncias e fazendas no Rio Grande do Sul, Uruguai e Brasil. Passo Fundo: UPF, 2008. 
MELLO, F. I. M. H. de. Falla dirigida à Assembléa Legislativa da Provincia de S. Pedro do Rio Grande do Sul pelo presidente Dr. Francisco Ignacio Marcondes Homem de Mello, em a segunda sessão da 121legislatura. Porto Alegre: Typ. do Rio Grandense, 1867. AHRS.

MARTINS, J. de S. Fronteira: a degradação do outro nos confins do humano. 2. ed. São Paulo: Contexto, 2009.

MATTOS, H. M. M. de. Ao sul da história: lavradores pobres na crise do trabalho escravo. São Paulo: Brasiliense, 1986. p. 15.

OSÓRIO, F. L. O. História do General Osório. Rio de Janeiro: Typographia Leuzinger \& Filhos, 1894.

SANTOS, C. R. A. dos. História da alimentação no Paraná. Curitiba: Fundação Cultural, 1995.

ZARTH, P. A. Do arcaico ao moderno: as transformações do Rio Grande do Sul rural no século XIX. Ijuí: Ed. Unijuí, 2002.

História agrária do Planalto Gaúcho (1850-1920). Ijuí: FideneUnijuí, 1997. 